\title{
Evaluation of immunity and protection in chicken administered a developed vaccine against predominant Middle Eastern strains of genotypes VI and VII of velogenic Newcastle Disease Virus
}

Soonham Sami Yaghmoor' ( $\nabla$ syaghmoor@kau.edu.sa )

King Abdulaziz University https://orcid.org/0000-0001-8186-465X

Taha Abdullah Kumosani

King Abdulaziz University Faculty of Sciences

Elie Kamil Barbour

King Abdulaziz University Faculty of Sciences

Othman Abubaker Baothman

King Abdulaziz University Faculty of Sciences

Research article

Keywords: broilers, developed, vaccine, v-NDV, immunity, protection

Posted Date: March 10th, 2020

DOI: https://doi.org/10.21203/rs.3.rs-16483/v1

License: (c) (1) This work is licensed under a Creative Commons Attribution 4.0 International License.

Read Full License 


\section{Abstract}

Background The velogenic-Newcastle Disease Virus (v-NDV) causes an important disease in chicken, associated with serious economic losses to the global poultry industry. This research evaluated the immunity in broilers administered a developed bivalent vaccine, aiming at protection against predominant Middle Eastern strains of genotypes VI and VII of v-NDV. The completely randomized design implemented in this evaluation included eight treatments, differing in birds being administered or deprived of the developed vaccine, with a difference in type of challenge, either by v-NDV strain(s) of genotype VI, VII, or both. Vaccination was administered subcutaneously at 6 and $21 \mathrm{~d}$ of age, followed by an intra-pectoral challenge at the age of $28 \mathrm{~d}$.

Results The acquired humoral immunity by vaccinated and challenged birds to Hemagglutinin $(H)$ protein was the highest at market age of $40 \mathrm{~d}$, compared to challenged birds deprived of vaccination, and to vaccinates deprived of challenge $(P<0.05)$. The same statistical difference pattern was obtained by the cell-mediated immunity (CMI), represented by birds' level of serum IFN- $\gamma$. The type of challenge by either strain(s) of genotype $\mathrm{VI}, \mathrm{VII}$, or $\mathrm{VII} \mathrm{VII}$ did affect statistically the cross reactivity of acquired humoral immunity specific to $\mathrm{H}$ protein of homologous versus heterologous strains. The absence of humoral immunity and the low IFN- $y$ levels at $28 \mathrm{~d}$ of age in challenged birds deprived of vaccination lead to highest mortality, and lowest performance compared to vaccinates and challenged, vaccinates and deprived of challenge, and unvaccinated-unchallenged birds $(P<0.05)$.

Conclusions The developed bivalent vaccine was able to induce enough humoral and CMI responses, enabling protection of the broilers against production losses by each of the three types of v-NDV challenges. It is recommended to conduct future studies to evaluate such types of vaccines in chicken breeders and commercial layers, reared in various world's zones with existing endemicity of v-NDV.

\section{Background}

The impact of v-NDV on poultry heath and economy of its global industry is highly significant [1-3]. The mortality losses in poultry due to v-NDV could reach to $100 \%$ [4], with significant negative impact on production performance of a few surviving birds $[2,5]$.

The predominant v-NDV strains in poultry of the Middle Eastern countries, including Israel, United Arab Emirates, Iraq, Jordan, Egypt, Lebanon, and Kingdom of Saudi Arabia belong mainly to genotypes VI and VII [6-8]. The genotype VI strains have affinity to respiratory, nervous, and gastrointestinal (GI) tract of the birds, causing apparent gross lesions of bluish ulcers in the intestine and petechial hemorrhage in the proventriculus [7]; however, the genotype VII strains have affinity to tissues of the respiratory and nervous system [9] causing apparent torticollosis and pneumonic signs [7].

Global reports are pointing at frequent failure of NDV-commercial vaccines in induction of acceptable immunity and protection against emerging strains of NDV [10]. Reports from the Middle East countries included also documentations of failure of various imported commercial vaccines in protection of poultry 
against v-NDV $[7,11]$. Other workers documented the persistent shedding of the NDV, in spite of the administration to poultry of the available vaccines in their market [12-14].

The hypothesis of this research predicted that a development of a bivalent autogenous vaccine constructed from predominant v-NDV strains of genotypes VI and VII will acquire enough immunity for protection against velogenic NewCastle Disease.

\section{Results}

\section{Pathological and molecular characteristics of v-NDV}

The pathological and molecular characteristics of V-NDV vaccine seed and challenge strains, included in this study, are shown in Table 1. The intracerebral pathogenicity indices of the genotypes VI and VII strains were 1.86 and 1.92, respectively. This high pathogenicity is confirmed by the high mean broiler's mortality percent, observed in the three field outbreaks caused by each strain of genotypes VI and VII, resulting in respective mean percent losses of 96.5 and $100.0(P>0.05)$. The velogenic nature of the two strains of genotypes VI and VII is molecularly demonstrated at their Fusion Protein Cleavage Site (FPCS), in which the amino acid Glutamine $(\mathrm{Q})$ is found at position 114 , surrounded by dibasic arginine $(\mathrm{R})$ at position 113 and lysine $(\mathrm{K})$ at position 115 .

Table 1

Pathogenicity and sequencing of fusion protein cleavage sites (FPCS) of predominant Middle Eastern vNDV strains of genotype VI and VII

\begin{tabular}{|llll|}
\hline Genotype & ICPI $^{\mathrm{a}}$ & $\begin{array}{l}\text { Mean } \\
\text { Mortality \% }\end{array}$ & FPCS $^{\mathrm{b}}$ \\
\hline $\mathrm{VI}$ & 1.86 & $96.5^{1}$ & RRQKRF \\
$\mathrm{VII}$ & 1.92 & $100.0^{1}$ & RRQKRF \\
\hline
\end{tabular}

a ICPI is the Intracerebral Pathogenicity Index, determined in 10 birds/genotype strain, according to protocol of OIE [15].

${ }^{\mathrm{b}}$ The Mean Mortality \% is recorded from three field outbreaks in broiler flocks caused by each genotype strain.

${ }^{\mathrm{C}}$ The amplification and sequencing at FPCS were performed according to previously documented protocol by Seal et al [16].

${ }^{1}$ Means in a column, followed by the same numerical superscript, are insignificantly different $(P>$ 0.05).

\section{Acquired Humoral Immunity By Vaccine And Challenge}


The completely randomized design (CRD) of this work is presented in Table 2, including eight treatments (TRTs) differing in birds being administered or deprived of the developed vaccine, and in type of challenge, either by strain(s) of genotype $\mathrm{VI}, \mathrm{VII}$, or $\mathrm{VI}+\mathrm{VII}$, in which the vaccination was performed at 6 and $21 \mathrm{~d}$ of age, and challenge administered at an age of $28 \mathrm{~d}$. The acquired humoral immunity, specific to either the H-protein of strains belonging to genotype VI or VII, was boosted similarly at 7 days post the second vaccination of birds allocated to TRTs $1,2,3$, and 7 . The different challenges by either the strain of genotypes VI, VII, or combined VI+ VII resulted in higher significant humoral immunity to H-protein of their homologous strains compared to the heterologous ones $(P<0.05)$; this significant difference in response is indicated by the numerical superscripts following the means presented in the last column of Table 3. The deprivation from vaccination, in the presence of either one of the three different challenges in birds of TRTs 4,5 , and 6 did result in significantly lower acquired immunity to the H-protein of strains used in the challenge at market age of $40 \mathrm{~d}$. The decay in acquired humoral immunity by the vaccine administered to birds of TRT 7 at 6 and $21 \mathrm{~d}$ of age, in absence of a challenge at $28 \mathrm{~d}$, led to a drop in HI titer, specific to H-protein of each of the two strains belonging respectively to genotypes $\mathrm{VI}$ and $\mathrm{VII}$, by the market age of $40 \mathrm{~d}$. The $\mathrm{HI}$ titer at $40 \mathrm{~d}$ of age in vaccinates that were deprived of challenge was significantly lower than the maintained titers obtained by vaccinates and challenged birds of TRTs 1,2 and $3(P<0.05)$. It is worth noting that the negative control birds of TRT 8 had a complete absence of $H I$ titer to $\mathrm{H}$ protein of genotypes $\mathrm{VI}$ and $\mathrm{VII}$ strains, an indication of an absence of exposure to such pathogens. 
Table 2

A brief presentation of the completely randomized design (CRD) adopted in this study for evaluation in broilers of the immunity and protection provided by the developed autogenous vaccine against v-NDV strains of genotypes VI and VII

\begin{tabular}{|c|c|c|c|}
\hline \multirow{2}{*}{$\begin{array}{l}\text { Treatment }^{a} \\
\text { (TRT) }\end{array}$} & \multirow[t]{2}{*}{ Vaccination $^{b}$} & \multicolumn{2}{|c|}{ Strain(s)' genotype used In challenge } \\
\hline & & VI & VII \\
\hline 1 & + & + & - \\
\hline 2 & + & - & + \\
\hline 3 & + & + & + \\
\hline 4 & - & + & - \\
\hline 5 & - & - & + \\
\hline 6 & - & + & + \\
\hline 7 & + & - & - \\
\hline 8 & - & - & - \\
\hline \multicolumn{4}{|c|}{${ }^{\mathrm{a} E a c h}$ TRT is comprised of four replicate isolation rooms, with 25 birds/room } \\
\hline \multicolumn{4}{|c|}{$\begin{array}{l}\text { bVaccination is administered at } 6 \text { and } 21 \mathrm{~d} \text { of age, subcutaneously in the neck, with a dose volume of } \\
0.5 \mathrm{ml} / \text { bird }\end{array}$} \\
\hline
\end{tabular}


Table 3

Acquired humoral immunity in broilers by the developed v-NDV vaccine ${ }^{a}$ and challenge ${ }^{b}$

\begin{tabular}{|c|c|c|c|c|c|c|}
\hline \multirow[t]{2}{*}{ TRT } & \multirow[t]{2}{*}{ Vaccination } & \multicolumn{2}{|c|}{$\begin{array}{l}\text { Strain(s)' genotype } \\
\text { used In challenge }\end{array}$} & \multicolumn{3}{|c|}{$\begin{array}{l}\text { Mean serum } \mathrm{HI} \text { titer }{ }^{c} \text { to } \mathrm{H} \text { protein of genotype VI/VII } \\
\text { strains at different ages (d) }\end{array}$} \\
\hline & & VI & VII & 21 & 28 & 40 \\
\hline 1 & + & + & - & $42.5^{1} / 43.7^{1}$ & $75.7^{1} / 79.8^{1}$ & $114.6^{1, \mathrm{e}} / 96.5^{1, \mathrm{f}}$ \\
\hline 2 & + & - & + & $40.8^{1} / 42.7^{1}$ & $73.8^{1} / 75.2^{1}$ & $92.3^{2, \mathrm{e}} / 122.0^{2, \mathrm{f}}$ \\
\hline 3 & + & + & + & $44.2^{1} / 43.0^{1}$ & $70.8^{1} / 72.2^{1}$ & $122.0^{1, \mathrm{e}} / 111.2^{1, \mathrm{e}}$ \\
\hline 4 & - & + & - & $0.0^{2} / 0.0^{2}$ & $0.0^{2} / 0.0^{2}$ & $52.7^{3, \mathrm{e}} / 25.2^{3, \mathrm{f}}$ \\
\hline 5 & - & - & + & $0.0^{2} / 0.0^{2}$ & $0.0^{2} / 0.0^{2}$ & $20.7^{4, e} / 48.0^{4, f}$ \\
\hline 6 & - & + & + & $0.0^{2} / 0.0^{2}$ & $0.0^{2} / 0.0^{2}$ & $N A^{d}$ \\
\hline 7 & + & - & - & $44.5^{1} / 41.7^{1}$ & $73.8^{1} / 75.2^{1}$ & $58.2^{3, e} / 55.0^{4, e}$ \\
\hline 8 & - & - & - & $0.0^{2} / 0.0^{2}$ & $0.0^{2} / 0.0^{2}$ & $0.0^{5, \mathrm{e}} / 0.0^{5, \mathrm{e}}$ \\
\hline
\end{tabular}

${ }^{a}$ Vaccination is administered at 6 and $21 \mathrm{~d}$ of age, subcutaneously in the neck, with a vaccine dose equivalent to $0.5 \mathrm{ml} / \mathrm{bird}$

${ }^{b}$ Challenge by either the genotype VI or VII strain, or by both, at an age of $28 \mathrm{~d}$

${ }^{\mathrm{C}}$ The serum $\mathrm{HI}$ titer is the Hemaaglutination - Inhibition titer quantifying the humoral antibodies specific to the $\mathrm{H}$ protein present in the $4 \mathrm{HA}$ units $/ 50 \mu \mathrm{L}$ of the genotype VI or VII strains used in the test against $0.1 \%$ of $\mathrm{c}-\mathrm{RBC}$

${ }^{d}$ NA stands for not applicable, due to the $100 \%$ mortality obtained by birds of TRT 6 , by the age of 40 days.

${ }^{1-5}$ Means of $\mathrm{HI}$ titer in a column, followed by different numerical superscripts, are significantly different at $\mathrm{P}<0.05$.

e,f Means of $\mathrm{HI}$ titer in numerator and denominator of a fraction located in a row of the last column, followed by different alphabet superscripts, are significantly different at $\mathrm{P}<0.05$.

\section{Acquired CMI By Developed Vaccine And Challenges}

The acquired $\mathrm{CMI}$ to vaccination and to challenge, quantified by the IFN- $\mathrm{Y}$ levels in sera of the differently treated birds, is shown in Table 4. The pattern of quantified INF- $\gamma$ is similar to that obtained by the humoral responses to H-protein of the two genotype-strains of v-NDV; more specifically, the highest IFN- $\gamma$ 
levels, post the vaccine booster delivered at $28 \mathrm{~d}$ of age, was obtained by the vaccinated birds of TRTs 1 , 2,3 , and 7 , with mean levels that were significantly higher than that obtained by all unvaccinated birds ( $P$ $<0.05$ ). This acquiring of higher CMI response at challenge age of 28 days in birds of TRTs 1,2 , and 3 helped to further rise significantly their INF-y levels at $12 \mathrm{~d}$ post challenge ( $40 \mathrm{~d}$ of age), compared to unvaccinated-challenged birds of TRTs 4,5 , and $6(P<0.05)$. It is worth noting that vaccinated birds, deprived of challenge (TRT 7), had a decay in INF-y level by the market age of $40 \mathrm{~d}$. In addition, the negative control birds of TRT 8 had a similar background levels of INF- $y$ at the three ages of 21,28 , and $40 \mathrm{~d}$.

Table 4

Acquired cell-mediated immunity (IFN-Y) in broilers by the vaccine ${ }^{\mathrm{a}}$ and challenge $\mathrm{e}^{\mathrm{b}}$

\begin{tabular}{|c|c|c|c|c|c|c|}
\hline \multirow[t]{2}{*}{ TRT } & \multirow[t]{2}{*}{ Vaccination } & \multicolumn{2}{|c|}{$\begin{array}{l}\text { Strain(s)' genotype used In } \\
\text { challenge }\end{array}$} & \multicolumn{3}{|c|}{$\begin{array}{l}\text { Mean serum IFN-Y of broilers at an age } \\
\text { (d) }\end{array}$} \\
\hline & & VI & VII & $21 \mathrm{~d}$ & $28 d$ & $40 \mathrm{~d}$ \\
\hline 1 & + & + & - & $720^{1}$ & $853^{1}$ & $978^{1}$ \\
\hline 2 & + & - & + & $713^{1}$ & $847^{1}$ & $1005^{1}$ \\
\hline 3 & + & + & + & $719^{1}$ & $850^{1}$ & $1012^{1}$ \\
\hline 4 & - & + & - & $612^{2}$ & $607^{2}$ & $804^{2}$ \\
\hline 5 & - & - & + & $593^{2}$ & $601^{2}$ & $797^{2}$ \\
\hline 6 & - & + & + & $606^{2}$ & $610^{2}$ & $N A^{c}$ \\
\hline 7 & + & - & - & $725^{1}$ & $817^{1}$ & $732^{3}$ \\
\hline 8 & - & - & - & $598^{1}$ & $590^{2}$ & $594^{4}$ \\
\hline \multicolumn{7}{|c|}{$\begin{array}{l}\text { a Vaccination is administered at } 6 \text { and } 21 \mathrm{~d} \text { of age, subcutaneously in the neck, with a dose volume of } \\
\text { vaccine equivalent to } 0.5 \mathrm{ml} / \mathrm{bird}\end{array}$} \\
\hline \multicolumn{7}{|c|}{${ }^{b}$ Challenge by either the genotype VI or VII strain, or by both at an age of $28 \mathrm{~d}$} \\
\hline \multicolumn{7}{|c|}{$\begin{array}{l}\text { CNA stands for not applicable, due to the } 100 \% \text { mortality obtained by birds of TRT } 6 \text { by the age of } 40 \\
\text { days }\end{array}$} \\
\hline \multicolumn{7}{|c|}{$\begin{array}{l}{ }^{1-4} \text { Means of IFN-Y in a column, followed by different numerical superscripts, are significantly } \\
\text { different at } P<0.05\end{array}$} \\
\hline
\end{tabular}

\section{Protection By Developed Vaccine}


The evaluation of the acquired protection in differently treated broilers by the developed vaccine, against different challenges, is based on birds' cumulative mean of mortality, feed conversion, and live body weight by the market age of $40 \mathrm{~d}$. The feed conversion is calculated by the division of the consumed feed/total body weight of broilers in each isolation room, and the mean was calculated from the feed conversion of birds in the four replicate rooms/treatment.

\section{Discussion}

The obtained intracerebral pathogenicity indices of the genotypes VI and VII strains were skewed towards the high scale of pathogenicity, as documented by the World Animal Health Organization [15]. In addition, the high mortality observed in field outbreaks caused by each genotype strain is in agreement with previous literature related to performance of broilers infected by similar strains $[7,16,17]$. The FPCS sequence of the two isolates is confirmative of the velogenic nature of the two genotypes of NDV [18].

The acquired humoral response to the second vaccination in TRTs $1,2,3$, and 7 is most likely due to class switch from IgM to IgG [19]; the high level of IgG isotype is expected to react efficiently against the different nature of challenges, administered at $28 \mathrm{~d}$ of age to birds of TRTs 1, 2, and 3 . The specific higher significant immune response to $\mathrm{H}$ protein of the homologous compared to heterologous strains used in the challenge indicates most likely a difference in the configuration of $\mathrm{H}$-protein epitopes present in strains of genotype $\mathrm{VI}$ and VII, in spite of the typical sequence of their FPCS [20, 21]. Differently challenged birds of TRTs 4,5 , and 6 , that were deprived of vaccination, had lower immune conversion by the market age, an in agreement data with a documentation confirming that a challenge by v-NDV in absence of sensitization by vaccines will lead to highly virulent challenge due to absence or presence of an unsubstantial immunity $[22,23]$. The fact that the vaccine-HI titer, at $40 \mathrm{~d}$ of age in vaccinates that were deprived of challenge (TRT 7), was significantly lower than the maintained titers obtained by vaccinated and challenged birds of TRTs 1,2 and 3, presents a proof of the ability of developed vaccine to prime the immune cells, enabling them to respond efficiently to the different challenges [24].

The data of Table 4, related to acquired CMI to vaccination and to challenge, quantified by the IFN-y levels in sera of the differently treated birds, document the impact of administering the developed vaccine at two different ages on inducing higher levels of IFN- $\gamma$; this response is indispensably needed for protection against v-NDV challenges administered at $28 \mathrm{~d}$ of age $[25,26]$. The data of INF- $\gamma$ levels post challenge is in agreement with documentations confirming an improvement in INF-y level of vaccinated - challenged birds compared to unvaccinated - challenged ones [27, 28]. In addition, a previous report showed that INF$y$ decays by time in vaccinated birds that are deprived of a secondary antigen exposure (challenge), as observed in birds of TRT 7, while the negative controls maintain similar low background levels of INF-y at different ages [28].

The significant higher performance of the vaccinated-challenged broilers (TRTs 1,2, and 3 ), in comparison to unvaccinated-challenged ones (TRTS 4, 5, and 6) (Table 5) is most likely due to the significant difference in the vaccine-acquired humoral and $\mathrm{CMI}$, an obtained data that is in agreement 
with previous documentations $[29,30,31,32,33]$. The similar high production parameters of lower mortality percent, lower feed conversion, and high live body weight in birds of TRT 7 and those of the negative controls reflect the safety of the developed killed vaccine on production [34], pending avoidance of stress, by careful handling of the birds during the subcutaneous administration of the vaccine.

Table 5 Performance ${ }^{\mathrm{a}}$ of broilers administered the developed v-NDV vaccine ${ }^{\mathrm{b}}$ and challenged ${ }^{\mathrm{c}}$ compared to other differently treated broilers

\begin{tabular}{|c|c|c|c|c|c|c|}
\hline \multirow[t]{2}{*}{ TRT } & \multirow[t]{2}{*}{ Vaccination } & \multicolumn{2}{|c|}{$\begin{array}{l}\text { Strain(s)' genotype used In } \\
\text { challenge }\end{array}$} & \multicolumn{3}{|c|}{ Performance of broilers up to $40 \mathrm{~d}$ of age } \\
\hline & & $\mathrm{VI}$ & VII & $\begin{array}{l}\text { Mean } \\
\text { Mortality \% }\end{array}$ & $\begin{array}{l}\text { Mean } \\
\text { FCR }\end{array}$ & $\begin{array}{l}\text { Mean live body } \\
\text { weight (g) }\end{array}$ \\
\hline 1 & + & + & - & $6.2^{1}$ & $1.87^{1}$ & $2350^{1}$ \\
\hline 2 & + & - & + & $5.4^{1}$ & $1.83^{1}$ & $2370^{1}$ \\
\hline 3 & + & + & + & $5.8^{1}$ & $1.84^{1}$ & $2367^{1}$ \\
\hline 4 & - & + & - & $98.3^{2}$ & $3.34^{2}$ & $1630^{2}$ \\
\hline 5 & - & - & + & $98.7^{2}$ & $3.53^{2}$ & $1598^{2}$ \\
\hline 6 & - & + & + & $100.0^{2}$ & $N A^{d}$ & NA \\
\hline 7 & + & - & - & $1.5^{3}$ & $1.75^{3}$ & $2395^{3}$ \\
\hline 8 & - & - & - & $1.8^{3}$ & $1.68^{3}$ & $2407^{3}$ \\
\hline
\end{tabular}

aCumulative performance up to market age of $40 \mathrm{~d}$

${ }^{b}$ Vaccination is administered at 6 and $21 \mathrm{~d}$ of age, subcutaneously in the neck, with a dose volume of equivalent to $0.5 \mathrm{ml} / \mathrm{bird}$

${ }^{c}$ Challenge by either the genotype VI or VII strain, or by both at an age of $28 \mathrm{~d}$

${ }^{d}$ NA stands for not applicable, due to the $100 \%$ mortality obtained by birds of TRT 6 by the age of 40 days

${ }^{1-3}$ Means of each performance parameter in a column, followed by different numerical superscripts, are significantly different at $\mathrm{P}<0.05$

\section{Conclusions}

This completely randomized design (CRD) allowed to analyze the obtained data statistically, evaluating the efficiency in broilers of the developed vaccine in its induction of protective humoral immunity to $\mathrm{H}$ protein of the v-NDV genotypes $\mathrm{VI}$ and $\mathrm{VII}$, and in acquiring significant levels of IFN- $y$ that provided an 
acceptable protection against the different nature of challenges, reflected by the high performance in vaccinated and challenged birds.

\section{Methods}

The experimental approach included a determination of the pathological and molecular characteristics of v-NDV strains involved in field outbreaks, preparation of autogenous bivalent v-NDV vaccine from the characterized predominant strains, preparation of different challenges, establishment of a completely randomized experimental design, and evaluation of the immunity and protection provided by the developed vaccine against the different challenges by v-NDV strains. The completely randomized experimental design enabled to address the scientific objectives, aiming at evaluation of the immunity and protection by the vaccine against predominant v-NDV strains.

\section{Pathological and molecular characteristics of v-NDV strains}

The intracerebral pathogenicity Index (ICPI) of v-NDV strains was determined by the protocol of Office Internationale des Epizooties (OIE), Manual of Standards for Diagnostic Tests and Vaccines [15]. Briefly, it involved the individual inoculation of each strain of genotype VI or VII into the brain of 10-day-old chicks, offsprings of NDV - free parents, obtained from our institution's hatchery, and monitoring their mortality at specific times. The reverse transcription - polymerase chain reaction (RT-PCR) was implemented to amplify the fusion protein cleavage site (FPCS) and its surrounding dibasic amino acids (35), while the sequencing of the generated amplicons was accomplished by Big-Dye terminator v.3.1 kit (Applied Systems, USA). The mean mortality percent, presented in Table 1, is obtained from field outbreaks in three respective broiler flocks, caused by each strain of genotype VI and VII.

\section{Preparation of autogenous bivalent v-NDV vaccine}

The preparation of an autogenous bivalent v-NDV vaccine, containing the pathologically and molecularly characterized strains of genotypes VI and VII, included the growth of each strain in chicken embryos of 10 day-old, obtained from our institution's hatchery. The inoculum applied of each strain through the allontoic membrane route was of 100 particles/100 ul/embryo. The harvesting of the propagated virus was at the day of mortality of the embryo (averaging $48 \mathrm{hr}$ post inoculation). Each harvested strain was adjusted to a strength of $128 \mathrm{HA}$ units against $0.1 \%$ of chicken-red blood cells (c-RBC) suspension. The adjusted harvest of each strain was inactivated by an overnight contact with $0.3 \%$ formalin; the absence of viral viability, post this contact, was checked by individual inoculation of each of the two formalized strains in $10 \mathrm{~d}$ - old embryos, followed by incubation for $3 \mathrm{~d}$, and testing the allontoic fluid of embryos for absence of agglutination against a $0.1 \%$ of c-RBC suspension. Equal volume of each adjusted strength of the two inactivated strains were pooled and emulsified with equal volume of mineral oil (viscometer reading of 40 SUS), with an inclusion of Arlacel C (Emulsifier) and Tween 20 (Surfactant), at the level recommended by the manufacturer (TCI Development, Shanghai, China). The emulsified preparation was 
passed in a colloidal mill at the following stator gap of 0.002 , resulting in water-in-oil micelles with average diameter of $1.2 \mu \mathrm{m}$.

\section{Preparation of different challenges}

Three different challenges were prepared from the harvested allontoic fluid, deprived of inactivation by formalin. The harvested genotype VI and VII strains was each adjusted to $10^{4} x$ Embryo Infectious Dose $_{50}$ $\left(E_{1 D_{50}}\right)$. Each bird assigned to specific challenge-treatment received genotype VI strain (TRTS 1 and 4 ) or VII strain (TRTS 2 and 5), in $50 \mu \mathrm{l} /$ bird, through the left pectoral muscle. Each challenged bird in TRTs 3 and 6 received $50 \mu$ of each genotype strain in the left pectoral muscle.

\section{Completely Randomized Experimental design}

The completely randomized experimental design is comprised of 8 Treatments (TRTs), with four replicate isolation rooms per treatment, in which each room contained 25 meat birds (Table 2), obtained at one-day old from our institution's hatchery. The day-old birds had a mean weight of $38 \mathrm{~g}$, and weight range of $37-$ $40 \mathrm{~g}$. The inclusion of this number of birds is indispensable for providing unbiased data that will allow the implementation of proper statistical analysis for comparison of assessed parameter means among the 8 different treatments. The day-old birds were randomly distributed in their pens, reared on the floor that is previously disinfected and covered with wood shaving; the birds were provided with continuous lighting, controlled temperature and feed formulation, following the instructions of Aviagen Co for Ross 308 broiler management. The birds had a continuous access to feeders and drinkers, while abiding by a welfare-related assessment to the broiler's environment throughout the whole trial. The specie of the experimental birds was Gallus gallus domesticus, Ross 308 strain, with ratio of males to females equivalent to $1: 1$. Birds of TRT 1 were vaccinated each with $0.5 \mathrm{ml}$ of the developed vaccine, delivered subcutaneously in the neck at 6 and $21 \mathrm{~d}$ of age, followed by challenge with genotype VI strain at $28 \mathrm{~d}$ of age. Birds of TRT 2 were similarly vaccinated but challenged with strain of genotype VII. Birds of TRT 3 were similarly vaccinated but challenged with strains of both genotype strains. Birds of TRTs 4, 5, and 6 were the positive controls, deprived of vaccination but respectively challenged with strains of genotype $\mathrm{VI}$, $\mathrm{VII}$, and $\mathrm{VI}+\mathrm{VII}$. Birds of TRT 7 were similarly vaccinated, but deprived of all types of challenge, while birds of TRT 8 were the negative controls, deprived of vaccination and challenge. The experiment was terminated at the market age of 40 days by euthanization, using an injection via the pectoral muscle, equivalent to $20 \mathrm{mg} / \mathrm{Kg}$ of tiletamine/zolazepam.

\section{Acquired humoral Immunity by Vaccine and Challenge}

The acquired humoral immunity in broilers, specific to the hemagglutinin protein of v-NDV present in the vaccine and challenge, was assessed by hemagglutination-inhibition $(\mathrm{HI})$ test [17]. Blood was collected from the brachial vein of each surviving bird at the ages of 21,28 , and $40 \mathrm{~d}$. Sera were separated from the 
collected coagulated blood; the HI titer of each serum was obtained against an antigen of $4 \mathrm{HA}$ units/50 $\mu \mathrm{l}$ of allontoic fluid containing the individual strain of genotype $\mathrm{VI}$ or genotype $\mathrm{VII}$, and including in the test a $0.1 \%$ of c-RBC suspension [36]. The $\mathrm{HI}$ titer of each sample detected the maximum dilution of the collected serum that still contained enough antibodies specific to $\mathrm{H}$ protein in the antigen, preventing this protein from binding to its receptor on the $\mathrm{c}-\mathrm{RBC}$, and by that inhibiting agglutination phenomenon.

\section{Acquired CMI to developed vaccine and challenges}

The same collected chicken sera were also analyzed for the level of IFN- $y$ at the ages of 21, 28, and $40 \mathrm{~d}$., reflecting the acquired $\mathrm{CMI}$ to developed vaccine and challenges in these birds $[37,38]$. The analysis of sera IFN- $\gamma$ was performed by sandwich-ELISA system, using a commercial kit by Shanhai CrystalDay Biotech Co., Yangpu district, Shanghai, China $[39,40]$.

\section{Protection by developed vaccine}

The evaluation of the acquired protection in differently treated broilers by the developed vaccine, against different challenges, is based on birds' cumulative mean of mortality, feed conversion, and live body weight by the market age of $40 \mathrm{~d}$. The feed conversion is calculated by the division of the consumed feed/total body weight of broilers in each isolation room, and the mean was calculated from the feed conversion of birds in the four replicate rooms/treatment.

\section{Statistics}

The One Way Analysis of Variance (ANOVA) was used to compare the means of HI titers, IFN- $\gamma$, feed conversion, and live body weight, among the eight different treatments; however, the means of cumulative mortality percent, up to market age of $40 \mathrm{~d}$, were compared among the 8 treatments by CHI Square $\left(\chi^{2}\right)$. The significant difference among means of each statistically analyzed parameter is reported at $\mathrm{P}<0.05$ [41].

\section{Abbreviations}

ANOVA: Analysis of variance; CMI: Cell mediated immunity; c-RBC: Chicken red blood cell; CRD: Completely randomized design; d: day; EID $_{50}$ : Embryo infectious dose ${ }_{50} ;$ FPCS: Fusion protein cleavage site; g: gram; Gl: Gastrointestinal; H protein: Hemagglutinin protein; HA: Hemagglutination test; HI test: Hemagglutination-Inhibition test; ICPI: Intracerebral pathogenicity index; IFN-Y: Interferon gamma; Ig: Immunoglobulin; K: Lysine; $\chi^{2}$ : Chi Square; $\mu \mathrm{L}$ : Microliter; $\mu \mathrm{m}$ : Micrometer; OIE: Office Internationale des Epizooties; Q: Glutamine; R: Arginine; RT-PCR: Reverse transcription-polymerase chain reaction; SUS: Sabolt universal seconds; TRT: Treatment; TRTS: Treatments 


\section{Declarations}

Acknowledgements

This project was funded by the Research and Development Office (RDO) at the Ministry of Education, Kingdom of Saudi Arabia (KAU), Grant no. HiQi-44-2019. The authors acknowledge with thanks the Research and Development at King Abdulaziz University for their technical support.

\section{Authors' contributions}

SSY, TAK, and EKB designed the studies. EKB, SSY, TAK, and OAB performed the animal and laboratory work. SSY and EKB wrote the project proposal and study protocols. EKB and SSY recorded the data, analyzed statistically, and reported. TAK and OAB aided in data interpretation and discussion. All authors contributed to writing, proof reading, and approval of the manuscript submission.

\section{Funding}

This project was funded by the Research and Development Office (RDO) at the Ministry of Education, Kingdom of Saudi Arabia (KAU), Grant no. HiQi-44-2019.

\section{Availability of data and materials}

The datasets and analysis are available upon requests made to the E-mail address of the manuscript's corresponding author.

\section{Ethics approval and consent to participate}

The experimentation on the broilers complied with the guide of the National Institutes of Health for the care and use of laboratory animals (NIH publication no.8023); this compliance was in agreement with the fundamental ethical principles for animal use, set by Basel Declaration Society, and the ethical guidelines of the International Council for Laboratory Animal Science. In addition, the procedures of this work were approved by the Research and Development Office (RDO) at the Ministry of Education, Kingdom of Saudi Arabia, pending a complete exclusion of all sorts of human experimentation.

\section{Consent for Publication}

Not applicable. The manuscript does not contain any individual person's data.

\section{Competing interests}

The authors declare that they have no conflict of interests among the authors or any other parties; in addition, the authors declare that they have no financial or non-financial interests that undermine, by any way, the objectivity, integrity, and value of this publication.

\section{Author details}


${ }^{1}$ Experimental Biochemistry Unit, King Fahd Medical Research Center and Production of Bioproducts for Industrial Applications Research Group, KAU, Jeddah, Saudi Arabia, Kingdom of Saudi Arabia (KSA).

${ }^{2}$ Biochemistry Department, Faculty of Science, King Abdulaziz University; Experimental Biochemistry Unit, King Fahd Medical Research Center and Production of Bioproducts for Industrial Applications Research Group, King Abdulaziz University (KAU), Jeddah, KSA. ${ }^{3}$ Adjunct to Department of Biochemistry, KAU, Jeddah, KSA; Director of R and D Department, Opticon Hygiene Consulting, Oechsli 7, 8807, Switzerland. ${ }^{4}$ Biochemistry Department, Faculty of Science, King Abdulaziz University, Jeddah, KSA

\section{References}

1. Center for Food Security and Public Health. Newcastle Disease. lowa: lowa State University; 2016. Available online at www.cfsph.iastate.edu/Factsheets/pdfs/newcastle_disease.pdf

2. Merck Online Veterinary Manual. Newcastle Disease in Poultry. 20th edition; Merck and Co., Inc: 2018. Available online at http://www.merckmanuals.com/vet/poultry/newcastle_disease_and_other_paramyxov

3. OIE. Manual of Diagnostic Tests and Vaccines for Terrestrial Animals. Chapter 2.3.14. Newcastle Disease. 2018. Available online at http://www.oie.int/fileadmin/Home/eng/Health_standards/tahm/2.03.14_NEWCASTLE_DIS.pdf

4. OIE. Terrestrial Animal Health Code. Chapter 10.9. Newcastle Disease. 2018. Available online at http://www.oie.int/index.php?id=169\&L=0\&htmfile=chapitre_nd.htm

5. United States Department of Agriculture, 2018. Virulent Newcastle Disease Virus (vNDV). Animal and Plant Health Inspection Service: 2019, pp. 1-5.

6. Aldous EW, Mynn JK, Banks J, Alexander DJ. A molecular epidemiological study of avian paramyxovirus type 1 (Newcastle disease virus) isolates by phylogenetic analysis of a partial nucleotide sequence of the fusion protein gene. Avian Pathol. 2003; 32:239-2577.

7. Mohamed MHA, Abdelaziz AM, Kumar S, Al-Habib MA, Megahed MM. Effect of phylogenetic diversity of velogenic Newcastle disease virus challenge on virus shedding post homologous and heterologous DNA vaccination in chickens, Avian Pathol. 2016; 45:228-234

8. Miller PJ, Decanini EL, Afonso CL. Newcastle disease: evolution of genotypes and the related diagnostic challenges. Infect Genet Evol. 2010; 10:26-35.

9. Samuel A, Nayak B, Paldurai A, et al. Phylogenetic and pathotypic characterization of Newcastle Disease Viruses circulating in West Africa and efficacy of a current vaccine. J Clin Microbiol. 2013; 51:771-781.

10. Cattoli G, Fusaro A, Monne I, Molia S, et al. Emergence of a new genetic lineage of Newcastle disease virus in West and Central Africa-implications for diagnosis and control. Vet Microbiol. 2010; 142:168-176.

11. Sedeik ME,Elbestawy AR, El-shall NA, et al. Comparative efficacy of commercial inactivated Newcastle disease virus vaccines against Newcastle disease virus genotype VII in broiler chickens. 
Poult Sci. 2019; 98:2000-2007.

12. Miller PJ, King DJ, Afonso CL, Suarez DL. Antigenic differences among Newcastle disease virus strains of different genotypes used in vaccine formulation affect viral shedding after a virulent challenge. Vaccine. 2007; 25:7238-7246.

13. Miller PJ, Estevez C, Yu Q, Suarez DL, King DJ. Comparison of viral shedding following vaccination with inactivated and live Newcastle disease vaccines formulated with wild-type and recombinant viruses. Avian Dis. 2009; 53:39-49

14. Dimitrov KM, Afonso CL, Yu Q, Miller PJ. Newcastle disease vaccines-A solved problem or a continuous challenge? Vet Microbiol. 2017; 206:126-136

15. OIE. Newcastle Disease. OIE Manual of Standards for Diagnostic Tests and Vaccines. OIE, Paris: 2000; pp 221-232.

16. Yi J, Liu C, Chen B, Wu S. Molecular characterization of a virulent genotype VIId strain of Newcastle disease virus from farmed chickens in Shanghai. Avian Dis. 2011; 55:279-284.

17. Bello MB, Yusoff KM, Ideris A, et al. Genotype diversity of Newcastle Disease Virus in Nigeria: Disease control challenges and future outlook. Advances Virol. 2018; Article ID 6097291, pp. 1-17.

18. Seal BS, King DJ, Locke DP, Senne DA, Jackwood MW. Phylogenetic relationships among highly virulent Newcastle Disease Virus isolates obtained from exotic birds and poultry from 1989 to 1996. J Clin Microbiol. 1998; 36:1141-1145.

19. Rahman MM, Uyangaa E, Han YW, et al. Modulation of systemic and mucosal immunity against an inactivated vaccine of Newcastle disease virus by oral co-administration of live attenuated Salmonella enterica serovar Typhimurium expressing chicken interleukin-18 and interferon-a. J Vet Med Sci. 2015; 77:395-403. 20. Hu Z, Hu S, Meng C, et al. Generation of a genotype VII Newcastle disease virus vaccine candidate with high yield in embryonated chicken eggs. Avian Dis. 2011; 55:391-397.

20. Miller PJ, Afonso CL, El Attrache J, et al. Effects of Newcastle disease virus vaccine antibodies on the shedding and transmission of challenge viruses. Dev Comp Immunol. 2013; 41:505-513.

21. Tirumurugaan KG, Kapgate S, Vinupriya MK, et al. Genotypic and Pathotypic Characterization of Newcastle Disease Viruses from India. PLoS ONE. 2011; 6:e28414.

22. Kang Y, Xiang B, Yuan R, et al. Phylogenetic and pathotypic characterization of Newcastle Disease Viruses circulating in South China and transmission in different birds. Front. Microbiol. 2016; 7:119.

23. Sarcheshmei M, Dadras H, Mosleh N, Mehrabanpour M. Comparative evaluation of the protective efficacy of different vaccination programs against a virulent field strain of the Newcastle Disease Virus in broilers. Braz J Poultry SCI. 2016; 18:363-370.

24. Susta L, Cornax I, Diel DG, et al. Expression of interferon gamma by a highly virulent strain of Newcastle disease virus decreases its pathogenicity in chickens. Microb Pathog. 2013; 61-62:73-83.

25. Sawant PM, Verma PC, Subudhi PK, et al. Immunomodulation of bivalent Newcastle disease DNA vaccine induced immune response by co-delivery of chicken IFN- $\gamma$ and IL-4 genes. Vet Immunol Immunopathol. 2011; 144:36-44. 
26. Ismail NM, El-Deeb AH, Emara MM, et al. IMS 1313-nanoparticle Mucosal Vaccine Enhances Immunity Against Avian Influenza and Newcastle Disease Viruses. Int J Poult Sci. 2018; 17:167-174.

27. Rohollahzadeh $\mathrm{H}$, Nili $\mathrm{H}$, Asasi $\mathrm{K}$, et al. Respiratory and GIT tract immune responses of broiler chickens following experimental infection with Newcastle disease's virus. Comp Clin Path. 2018; 27:1241-1255.

28. Kumar S, Nayak B, Collins PL, Samal SK. Evaluation of the Newcastle disease virus F and HN proteins in protective immunity by using a recombinant avian paramyxovirus type 3 vector in chickens. J Virol. 2011; 85: 6521-6534.

29. Firouzamandi M, Moeini H, Hosseinietal SD. Preparation, characterization, and in ovo vaccination of dextran-spermine nanoparticle dna vaccine coexpressing the fusion and hemagglutinin genes against Newcastle disease, Int. J. Nanomed. 2016; 11:259-267.

30. Bello MB, Yusoff K, Ideris A, et al. Diagnostic and vaccination approaches for Newcastle disease virus in poultry: the current and emerging perspectives. Biomed Research International, 2018; Article ID7278459, pp. 1-18.

31. Cardenas-Garcia S, Dunwoody RP, Marcano V, et al. 2016. Effects of chicken interferon gamma on Newcastle disease virus vaccine immunogenicity. PLoS One. 2016; 11:e0159153.

32. Susta L, Cornax I, Diel DG, et al. Expression of interferon gamma by a highly virulent strain of Newcastle disease virus decreases its pathogenicity in chickens. Microb Pathog. 2013;73-83.

33. El-Dabae WH, Hussein HA, Rohaim MA, et al. Saponin-adjuvanted vaccine protects chickens against velogenic Newcastle disease virus. Arch Virol. 2018; 163:2423-2432.

34. Seal BS, King DJ, Joyce D. Bennett JD. Characterization of Newcastle Disease Virus isolates by reverse transcription PCR coupled to direct nucleotide sequencing and development of sequence database for pathotype prediction and molecular epidemiological analysis. J Clin Microbiol. 1995; 33:2624-2630.

35. Brown J, Resurreccion RS, Dickson TG. The relationship between the Hemagglutination-Inhibition test and the Enzyme-Linked Immunosorbent Assay for the detection of antibody to Newcastle disease. Avian Dis. 1990; 34:585-587.

36. Karaca K, Kim IJ, Reddy SK, Sharma JM. Nitric oxide inducing factor as a measure of antigen and mitogen-specific Tcell responses in chickens. J Immunol Methods. 1996; 192:97-103.

37. Karaca K, Kim IJ, Reddy SK, Sharma JM. Nitric oxide inducing factor as a measure of antigen and mitogen-specific Tcell responses in chickens. J Immunol Methods. 1996; 192:97-103.

38. Whiteside TL. Cytokine measurements and interpretation of cytokine assays in human disease. J Clin Immunol. 1994; 14:327-339.

39. Mateu de A, Robert JH, Richard H, Joan K, et al. Quantitative detection of porcine interferon-gamma in response to mitogen, superantigen and recal viral antigen. Vet Immunol Immunopathol. 1998; 61:265-277.

40. MSTAT. Michigan State University, East Lancing, Ml: 2019. Version 6.5.1. 


\section{Supplementary Files}

This is a list of supplementary files associated with this preprint. Click to download.

- FilledARRIVEChecklistofManuscriptBVETD2000009.docx 